\title{
An SEM compatible plasma cell for in-situ studies of hydrogen-material interaction
}

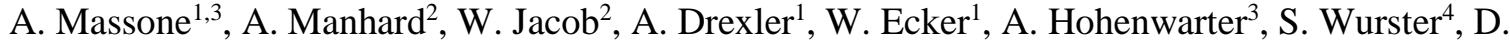 \\ Kiener $^{3}$ \\ 1. Materials Center Leoben, Forschungs GmbH, 8700, Leoben, Austria \\ 2. Max-Planck-Institut für Plasmaphysik, Boltzmannstr. 2, D-85748 Garching, Germany \\ 3. Department Materials Science, Chair of Materials Physics, Montanuniversität Leoben, 8700, Leoben, Austria \\ 4. Erich Schmid Institute of Materials Science, 8700, Leoben, Austria \\ Corresponding author: Agustina Massone \\ Email: agustina.massone@mcl.at \\ Telephone: +43 (0) 3842-804-410
}

\section{$\underline{\text { Abstract }}$}

An in-situ hydrogen (H) plasma charging and in-situ observation method was developed to continuously charge materials while tensile testing them inside a scanning electron microscope (SEM). The present work will introduce and validate the setup and showcase an application allowing high-resolution observation of H-material interactions in a Ni-based alloy, the alloy 718. The effect of charging time and pre-straining was investigated. Fracture surface observation showed the expected ductile microvoid coalescence behaviour in the uncharged samples, while the charged ones displayed brittle intergranular and quasi-cleavage failure. With the in-situ images, it was possible to monitor the sample deformation and correlate the different crack propagation rates with the load-elongation curves. H-charging reduced the material ductility, while increasing pre-strain decreased hydrogen embrittlement susceptibility due to the suppression of mechanical twinning during the tensile test and, therefore, a reduction of $\mathrm{H}$ concentration at grain and twin boundaries. All the presented results demonstrated the validity of the method and the possibility of in-situ continuously charging of materials with $\mathrm{H}$ without presenting any technical risk for the SEM.

\section{$\underline{\text { Keywords }}$}

Hydrogen Embrittlement

Scanning electron microscope

In-situ test

Plasma

Ni-based alloy 


\section{$\underline{\text { Introduction }}$}

Considering an increasing depletion of fossil fuels and the necessity to implement alternative sources of energy to mitigate the serious climate changes, hydrogen $(\mathrm{H})$ is believed to be a promising future fuel for energy storage [1]. With this aim, materials have to be developed to transport and store $\mathrm{H}$, and the most critical factor for safe use is a loss in ductility due to hydrogen embrittlement (HE). Nowadays, the use of high-strength structural materials for lightweight applications becomes a necessity. Although it is possible to develop materials with high tensile strength and high fracture toughness, many of them can be affected by $\mathrm{H}$ [2], leading to a severe degradation of their outstanding properties if exposed to $\mathrm{H}$ environments. Moreover, materials such as Ni-based superalloys, which are mainly used in the gas and oil industry, have to withstand extreme conditions avoiding stress corrosion and hydrogen embrittlement failure [3].

HE is a severe type of failure that affects a large number of metals and alloys. The first detrimental effects of $\mathrm{H}$ were reported in the 1870s Johnson [4]. He observed that the toughness of iron was reduced when immersed in acid and that this effect was reversible on a macroscopic point of view, concluding that $\mathrm{H}$ was responsible for this phenomenon. Since Johnson's first reports, many scientists have studied the nature, causes and control of Hrelated degradation of metals on a microscopic scale [5-18]. This has led to numerous controversial findings and interpretations on the HE mechanisms [5-7, 18].

There are two main approaches in literature to study the HE effects. One is focused on the analysis of post-mortem morphological features. From these studies, two mechanisms were proposed. The hydrogen enhanced decohesion mechanism (HEDE), first suggested by Gerberich and Oriani [5, 12], postulates that H diffuses to crack fronts, and the local accumulation of $\mathrm{H}$ reduces the cohesion between atoms. This reduction in cohesion in $\mathrm{Ni}$ and the effect of some co-segregation elements was recently studied by He et al. [19]. Thus, in the presence of $\mathrm{H}$, the local maximum tensile stresses, controlled by the externally applied load and the crack front geometry, can exceed the maximum lattice cohesive force, giving rise to failure. Following this approach, Lynch proposed the adsorption induced dislocation emission (AIDE) mechanism [6, 20, 21], which states that $\mathrm{H}$ promotes dislocation emission from crack tips as a result of the weakening of interatomic bonds, implying that a greater proportion of dislocation activity results in faster crack growth.

The second approach for studying HE effects focuses on in-situ experiments. Robertson, Birnbaum and Sofronis [7, 22-24] proposed the hydrogen enhanced localized plasticity (HELP) mechanism based on in-situ environmental transmission electron microscopy (TEM) results. They suggested that $\mathrm{H}$ increases the rate of dislocation generation and velocity. Furthermore, $\mathrm{H}$ lowers the interaction between dislocations and elastic obstacles, leading to a reduction in shear stress for dislocation motion and promoting localized deformation.

One important aspect in the study of $\mathrm{HE}$ is the $\mathrm{H}$ source. From the charging point of view, $\mathrm{H}$ can either be pre-charged into the material or introduced in-situ. In the first case, considering that $\mathrm{H}$ exhibits fast diffusion in some materials [25], there is a significant probability that outgassing occurs. In-situ charging experiments prevent this issue by continuously supplying $\mathrm{H}$. Among these, the most popular ones are performed either with $\mathrm{H}$ gas at high pressure [8] or by electrochemical cathodic charging [9, 10]. However, in these cases, a high-resolution observation during deformation is difficult. In-situ observation during $\mathrm{H}$ charging is limited by the difficulty of operating a $\mathrm{H}$ source in a high vacuum environment. Environmental SEM and TEM have been used to test $\mathrm{H}$ 
effects in an H environment with nanomechanical testing [26, 27], allowing an observation of the defect behaviour, but with a limited field of view and potential sample size effects [28].

A third charging possibility, rarely developed though, is plasma charging. Plasmas are generated by supplying energy to a neutral gas causing the formation of charge carriers. There are various ways to supply the necessary energy for plasma generation. The most commonly used method of generating and sustaining a lowtemperature laboratory plasma is by applying an electric field to a neutral gas [29]. Any volume of neutral gas always contains a few electrons and ions and when the electric field is applied, these free charged particles are accelerated and collide with atoms and molecules in the gas, thereby creating new charged particles. Thus, an avalanche of charged particles is generated, which is eventually balanced by charge carrier losses to arrive at a steady-state plasma.

Wang et al. [30, 31] used low-pressure H plasma in an environmental SEM to study HE of a ferritic alloy with in-situ mechanical testing by connecting a plasma cleaner to the SEM chamber. Unfortunately, they found in-situ observation by normal SEM mode to be limited and were not able to perform in-situ imaging with highvoltage. The challenge in this case lies on the difficulty of having an in-situ observation in the $\mathrm{H}$ environment due to the high $\mathrm{H}$ flammability. Consequently, their investigations were only feasible when the chamber was again evacuated to the high-vacuum state after charging.

\section{Experimental method}

To overcome these issues and establish more defined ways to study $\mathrm{H}$-material interactions, a new in-situ $\mathrm{H}$ charging method with plasma charging has been developed to allow in-situ $\mathrm{H}$ charging inside an SEM while performing a macroscopic deformation test. Therefore, a miniaturized plasma cell using Radio Frequency (RF) power was built. This configuration consists of two electrodes confined in a vacuum vessel. One of the electrodes is grounded while the other one is powered by a high frequency $(13.56 \mathrm{MHz})$ power source, and an exchangeable working gas is fed into the system through an inlet. In this study, deuterium gas was chosen so that in the future the retained $\mathrm{H}$ content can be determined by nuclear reaction analysis or by thermal desorption. Furthermore, a matchbox is necessary to match the impedances of the RF generator and the plasma to optimize power absorption [32].

Fig. 1-a shows a scheme of the in-situ setup in the SEM. A stainless steel cup of $25 \mathrm{~mm}$ diameter, $20 \mathrm{~mm}$ height and an aperture of $2 \mathrm{~mm}$ is used as the vessel and powered electrode, while the grounded sample acts as counter electrode. Tensile specimens were fabricated by electrical discharge machining with the geometry of 32 $\mathrm{mm}$ length, $5 \mathrm{~mm}$ width and thicknesses ranging between 0.65 and $1.40 \mathrm{~mm}$. Since the aperture of the powered vessel cup is $2 \mathrm{~mm}$ diameter, only the centre region of the samples was charged with $\mathrm{H}$. This allows $\mathrm{H}$ charging of a localized region of the sample where the in situ observation will be performed. To provide a faster $\mathrm{H}$ diffusion through the thickness of the material, a reduction in the thickness to approximately $0.2 \mathrm{~mm}$ was made in the charged area (see Fig. 1-b). Furthermore, since the charging is conducted only from the bottom of the samples, a contamination free top surface for SEM observation is provided. An Indium wire gasket was used to seal the sample to the cell, and a Teflon disk with an aperture in the centre of the sample was used to attach the sample to the Indium seal. This arrangement keeps the cell not only sealed, but also allows a friction-less displacement of the sample during the mechanical test as well as the surface observation through the electron beam. 

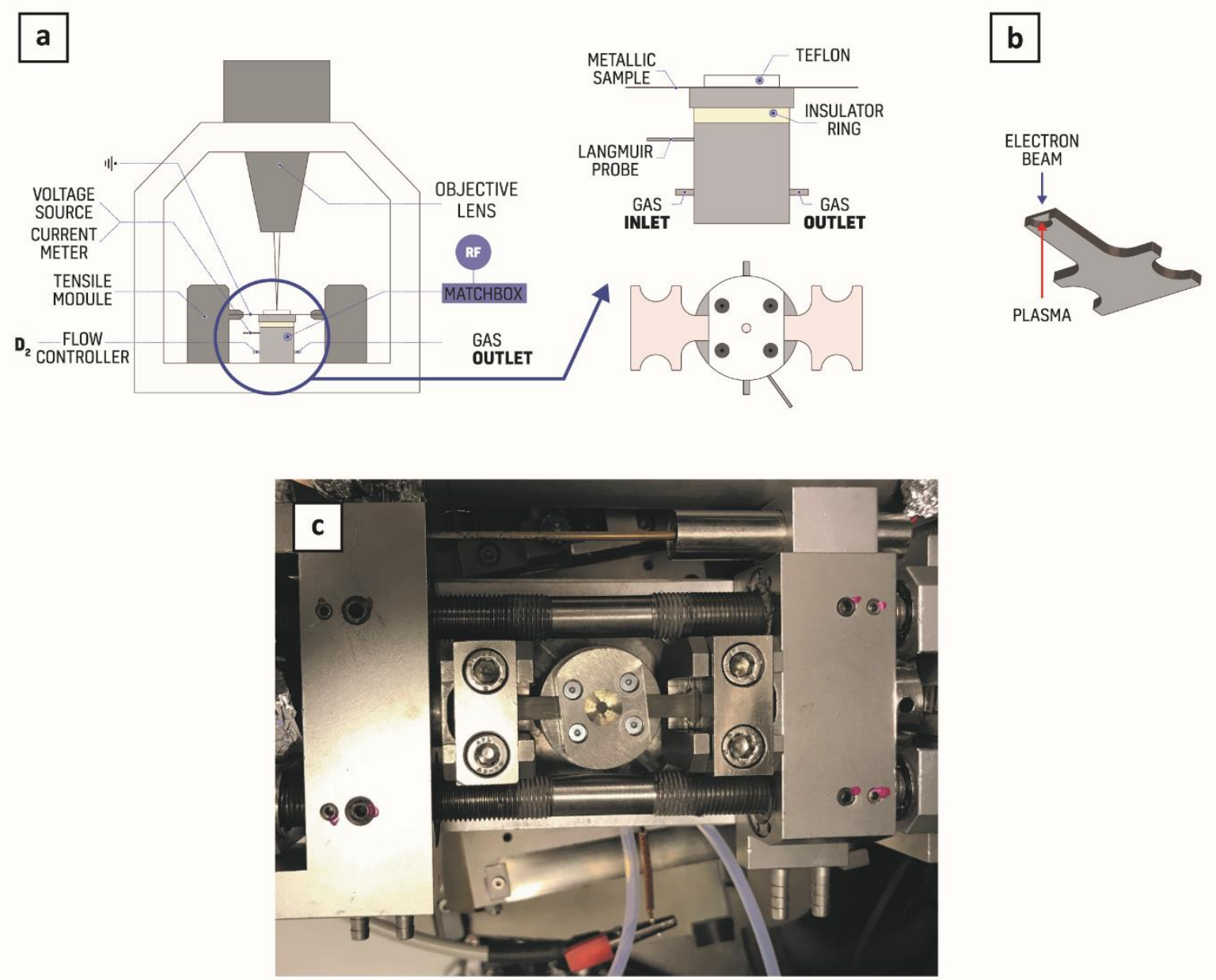

Fig. 1. (a) Scheme of miniaturized plasma cell implemented in the SEM. (b) Cross section of tensile sample with indicated charging and observation directions. (c) Top view of the plasma device with the tensile stage inside the SEM

As the sample geometry deviates from standardized geometries, a fully three-dimensional mechanical finite element (FE) simulation was conducted to account for the heterogeneity of stress distribution across the thinned centre region of the samples, as shown in Fig. 2. The thickness of the centred region was $200 \mu \mathrm{m}$ in the model. The FE modelling has been performed with the commercial software package Abaqus [33]. The sample geometry is meshed using tetrahedral continuum elements with quadratic shape functions. An average element size of $0.05 \mathrm{~mm}$ was used in the thinned area of the sample. In the rest of the model, the element size length was $0.2 \mathrm{~mm}$. The applied material model describes the elasto-plastic behaviour of the solution-annealed Alloy 718 by means of a von Mises yield function with isotropic hardening. The hardening function is based on a data field approach considering the measured true stress-true strain dependency. The Young's modulus was assumed to be $210 \mathrm{GPa}$ and the Poisson's ratio was 0.3 . 

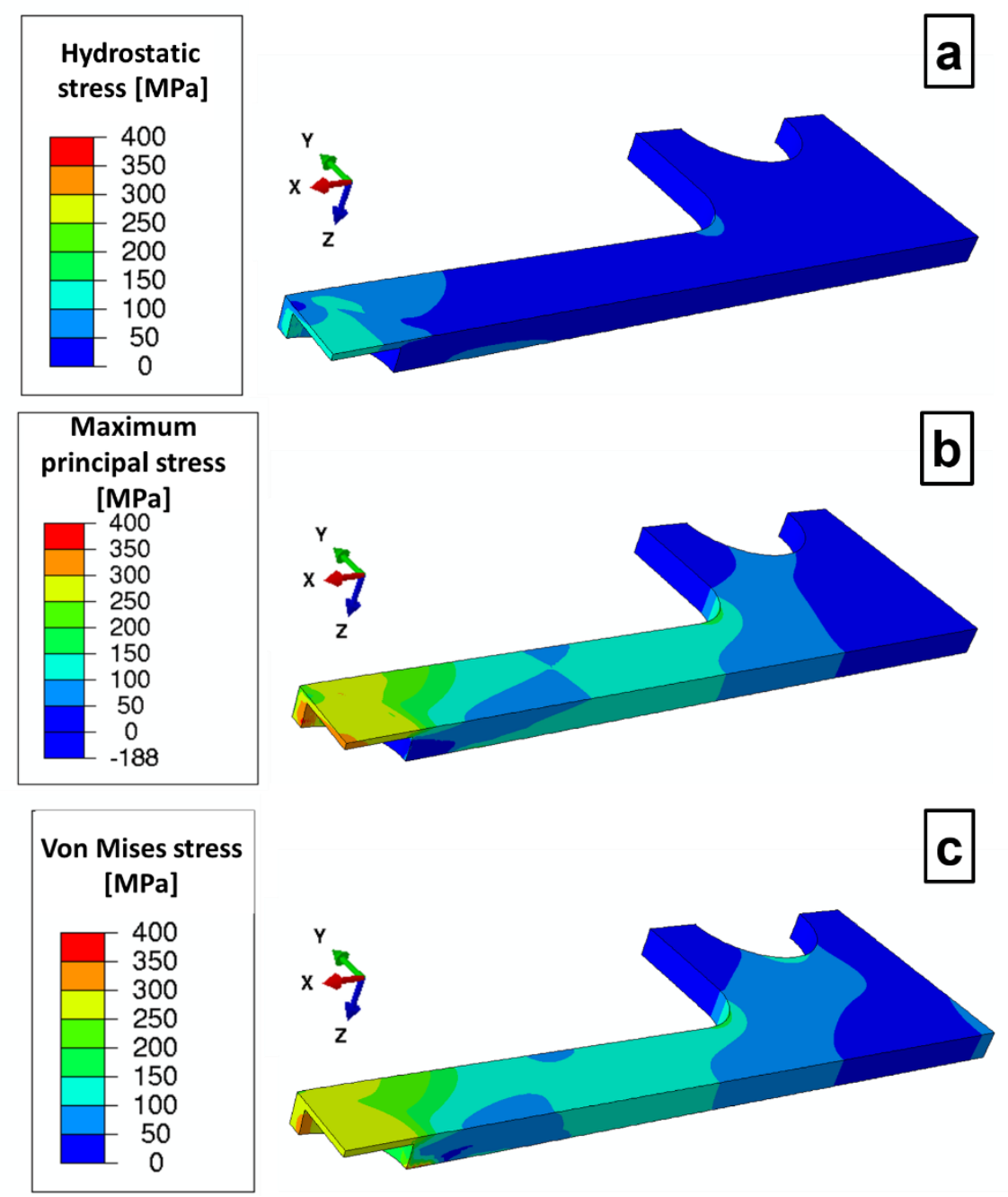

Fig. 2. Stresses distribution in cross section of the sample. (a) Hydrostatic stress (MPa). (b) Maximum principal stress $(\mathrm{MPa})$. (c) Von Mises stress $(\mathrm{MPa})$. The pictures were taken for a plastic strain of $1 \%$ in the middle of the thinned area where the plasma charges the sample from below.

The tests were performed in an SEM Stereoscan 440 operated at an acceleration voltage of $10 \mathrm{kV}$ for imaging. A Kammrath \& Weiss tensile stage, equipped with a $10 \mathrm{kN}$ load cell and an inductive displacement sensor was used for the mechanical tests. The accuracy of the load cell is in the order of $\sim 1 \mathrm{~N}$, and the accuracy of the displacement sensor is $\sim 0.5 \mu \mathrm{m}$. For all tests, a displacement rate of $0.2 \mu \mathrm{m} / \mathrm{s}$ was set. Teflon tubes were used for gas inlet and outlet inside the SEM chamber and the gas flow was controlled with a Bronkhorst Mass Flow Controller In-Flow. A CESAR RF power generator with an impedance matching box served to supply energy to the deuterium gas to produce plasma. For delivering the energy to the plasma cell, a $50 \Omega$ coaxial cable was selected.

To investigate the plasma parameters, Langmuir probe measurements were conducted in a first prototype of the plasma cell built at the Max-Planck-Institut für Plasmaphysik, in Garching. The Langmuir probe consisted of a tungsten wire of $5 \mathrm{~mm}$ length and $0.15 \mathrm{~mm}$ diameter. The gas flow used was $0.75 \mathrm{sccm}$ (standard cubic centimetres per minute) with power ranging from 0.8 to $1.4 \mathrm{~W}$. The resulting DC bias voltage was $100 \mathrm{~V}$. The current (I) drained by the probe for each bias voltage (U) supplied was measured as shown in Fig. 3. 


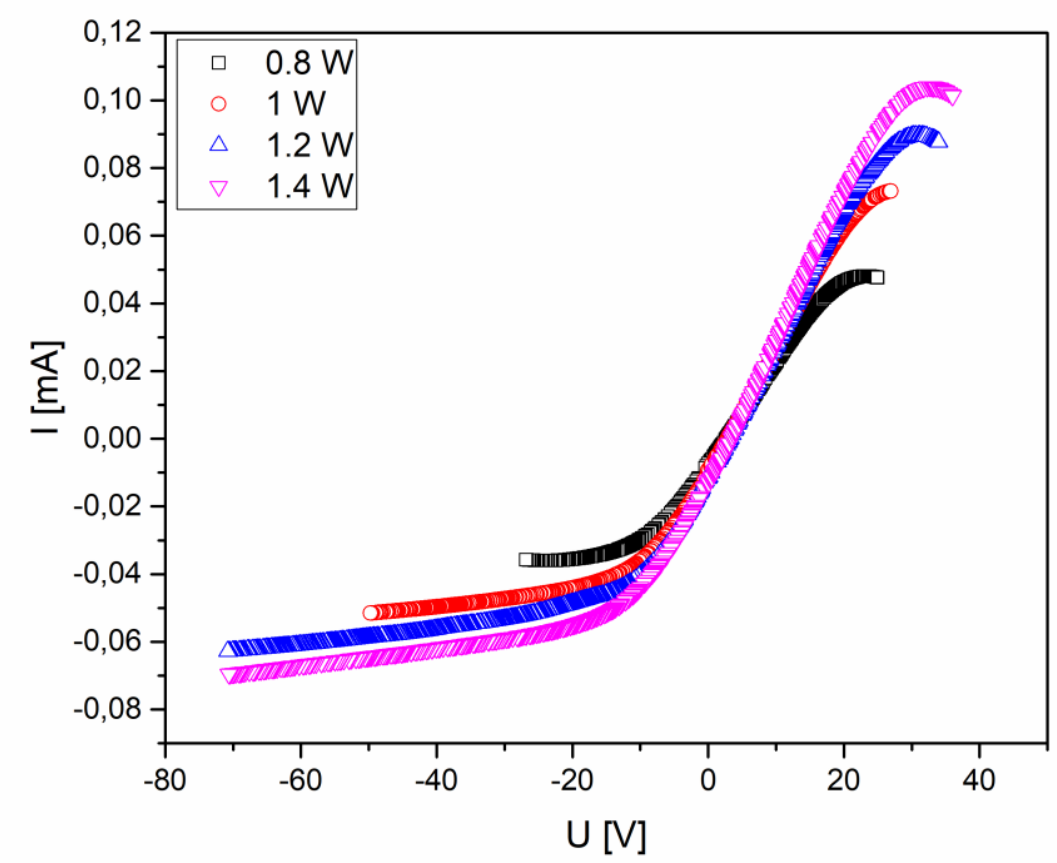

Fig. 3. Langmuir Probe curves of the plasma cell prototype for a gas flow of $0.75 \mathrm{sccm}$ and power ranging from 0.8 to $1.4 \mathrm{~W}$. With these curves, electron temperature $(\sim 1 \mathrm{eV})$ and ion flux $\left(\sim 10^{20} \mathrm{~m}^{-2} \mathrm{~s}^{-1}\right)$ were calculated

The following equations $[34,35]$ were used to analyse the curves:

$$
\begin{gathered}
I=0.61 n_{e} e S \sqrt{\frac{T_{e}}{m_{i}}\left(1-\exp \left(-\frac{e\left(\varphi_{f l}-U\right)}{T_{e}}\right)\right)} \\
n_{e}=1.42 * \frac{I s \sqrt{m_{i}}}{S \sqrt{V_{p}-U}} \\
\eta=3 * 0.61 \sqrt{\frac{T_{e}}{m_{i}}} n_{e}
\end{gathered}
$$

where $n_{e}=$ electron density, $e=$ elementary charge, $S=$ probe surface $=l \pi d, T_{e}=$ electron temperature, $\varphi_{f l}=$ floating potential $(I=0), U=$ probe potential, $m_{i}=$ ion mass $=6 \mathrm{amu}\left(\mathrm{D}_{3}{ }^{+}\right.$ions), $I_{s}=$ ion saturation current, $V_{p}$ $=$ plasma potential and $\eta=$ ion flux.

The exponential part of the I-U curve (eq. 1), if plotted semi-logarithmically versus the probe potential $\mathrm{U}$, should be a straight line and the slope of the curve is $1 / \mathrm{T}_{\mathrm{e}}$. To determine the plasma potential, one method is to take the point where $I_{e}$ starts to deviate from exponential growth, that is where $\mathrm{I}_{e}{ }^{\prime}(U)$ is maximum or $\mathrm{I}_{e}$ " $(U)$ is zero [36]. For a gas flow of $0.75 \mathrm{sccm}$ and power between 0.8 and $1.4 \mathrm{~W}$, the resulting electron densities (eq. 2) were in the range of $10^{16} \mathrm{~m}^{-3}$, electron temperatures around $1 \mathrm{eV}$ and ion fluxes (eq. 3) in the range of $10^{20} \mathrm{~m}^{-2} \mathrm{~s}^{-1}$.

\section{Material}


To demonstrate the versatility of the design, a Ni-based alloy (Alloy 718) in the solution annealed condition, with a grain size of $\sim 100-200 \mu \mathrm{m}$, was tested with this novel method. This material was chosen as a model material to be examined, since its microstructure and its susceptibility to $\mathrm{H}$ have been reported previously in literature [37-42], permitting comparison to the in situ data. The composition of the material is shown in Table I, in conformity to AMS specification.

Table I. Chemical composition of Alloy 718 [wt. \%]

\begin{tabular}{|l|l|l|l|l|l|l|l|l|l|l|l|l|l|l|}
\hline $\begin{array}{l}\text { Ni } \\
\text { (+Co) }\end{array}$ & $\mathbf{C r}$ & $\mathbf{F e}$ & $\mathbf{N b}$ & $\mathbf{M o}$ & $\mathbf{T i}$ & $\mathbf{A l}$ & $\mathbf{C o}$ & $\mathbf{C}$ & $\mathbf{M n}$ & $\mathbf{S i}$ & $\mathbf{P}$ & $\mathbf{S}$ & $\mathbf{B}$ & $\mathbf{C u}$ \\
\hline $50-55$ & $17-$ & Balance & $4.75-$ & $2.8-$ & $0.65-$ & $0.2-$ & 1 & 0.08 & 0.35 & 0.35 & 0.015 & 0.015 & 0.006 & 0.30 \\
& 21 & & 5.50 & 3.3 & 1.15 & 0.8 & $\max$ & $\max$ & $\max$ & $\max$ & $\max$ & $\max$ & $\max$ & $\max$ \\
\hline
\end{tabular}

With the ion flux $\eta$ calculated from the Langmuir Probe data and the H diffusion coefficient in Alloy 718 [43], $\mathrm{H}$ concentration can be calculated. Assuming $\mathrm{D}_{3}{ }^{+}$ions at $100 \mathrm{~V}$ bias (i.e., $33 \mathrm{eV} / \mathrm{D}$ ) and a pure Ni target for simplicity (the alloy has a similar stopping power); the mean implantation depth $r_{\text {mean }}$ was calculated using a Monte-Carlo program, SDTrim.SP 6.0 [44]. The resulting $r_{\text {mean }}$ is $1.15 \mathrm{~nm}$. About $41 \%$ of the particles are implanted (the remaining $59 \%$ are reflected directly and do not contribute to the D concentration).

A simple analytical model [45] was assumed considering the case of diffusion-limited recombination at both sample surfaces. Since H solubility in Alloy 718 is low, solute $\mathrm{H}$ has a strong tendency to leave the sample once it reaches the surface. Assuming that recombination of $\mathrm{H}$ to $\mathrm{H}_{2}$ (or $\mathrm{D}$ to $\mathrm{D}_{2}$ ) is fast (reasonable for a clean surface exposed to plasma) the entire amount of H/D diffusing to the surface of the sample is immediately lost, i.e., the solute $\mathrm{H} / \mathrm{D}$ concentration at the plasma-exposed surface is 0 . Furthermore, the sample thickness $(200 \mu \mathrm{m})$ is much larger than the implantation range $(\sim 1 \mathrm{~nm})$ and any H/D that is implanted starts diffusing. In steady state, there is a constant H/D concentration gradient towards either surfaces, according to Fick's law:

$$
j=-D_{H} * \frac{\partial \rho_{H}}{\partial x}
$$

where $j=$ diffusion flux, $D_{H}=\mathrm{H}$ diffusion coefficient, $\rho_{H}=\mathrm{H}$ density.

The highest concentration is reached at the implantation range and it decays linearly towards either surface. Since the implanted surface is much closer to the implantation range than the opposite surface (which is observed by the SEM), this gradient is steeper and, accordingly, the diffusive flux towards this surface is larger. In good approximation, nearly all deuterium particles that are implanted diffuse back to the plasma-exposed surface and desorb there. Only a small fraction of the implanted flux $\left(0.001 \mu \mathrm{m} / 200 \mu \mathrm{m}=5^{*} 10^{-6}\right)$ diffuses into the bulk and, eventually, to the observed surface.

The following equation can be used to calculate the concentration maximum at the implantation range (the fraction of diffusion into the bulk can safely be neglected):

$$
C_{\text {max }}=\frac{r_{\text {mean } *(1-R) * \eta}}{\rho * D_{H}}
$$


where $C_{\max }=$ maximum H/D concentration, $R=$ reflection coefficient, $\eta=$ ion flux, $\rho=$ density, $D_{H}=\mathrm{H}$ diffusion coefficient.

This leads to a maximum H solute concentration between $\sim 120-150 \mathrm{ppm}$. Since the decay towards the back surface is assumed linear, the average solute concentration would be exactly half of that, i.e. $\sim 60-75$ ppm.

\section{$\underline{\text { Testing conditions }}$}

Two different batches of samples were tested with different charging conditions. The first set (samples $\mathrm{S} 1$ to S4 in Table II) was tested with different charging times, from uncharged conditions to $1 \mathrm{~h}$ of pre-charging. The pre-charged samples were also in-situ charged while testing, taking into account that the tests lasted approximately one hour. In the second set (S5 to S7 in Table II), the pre-straining effect was analysed. S5 was used as an uncharged and not pre-strained reference sample. S6 sample was pre-strained for $370 \mu \mathrm{m}$ (pre yield point, which corresponds to approximately $7.7 \%$ strain in the centre of the sample) while S7 for $400 \mu \mathrm{m}$ (post yield point, corresponding to $8.3 \%$ strain in the same region as sample S6). Both samples were held in the strained condition and were pre-charged with hydrogen for $4 \mathrm{~h}$. Afterwards, the tensile test was continued until failure. All tests were conducted under constant strain rate conditions with a constant displacement rate of $0.2 \mu \mathrm{m} / \mathrm{s}$.

Table II. Overview of Alloy 718 samples tested

\begin{tabular}{|c|c|c|c|c|}
\hline Sample & Testing condition & $\begin{array}{c}\text { Overall } \\
\text { thickness }(\mathbf{m m})\end{array}$ & $\begin{array}{c}\text { Reduced } \\
\text { thickness } \\
(\mathbf{m m})\end{array}$ & $\begin{array}{c}\text { Failure time } \\
(\mathbf{m i n})\end{array}$ \\
\hline S1 & Uncharged & 0.65 & 0.20 & 72.58 \\
\hline S2 & Charged while testing & 0.65 & 0.23 & 67.5 \\
\hline S3 & $\begin{array}{c}\text { 0.5 h pre-charged+ } \\
\text { charged while testing }\end{array}$ & 0.65 & 0.20 & 70.25 \\
\hline S4 & $\begin{array}{c}1 \text { h pre-charged+ } \\
\text { charged while testing }\end{array}$ & 0.65 & 0.23 & 69.3 \\
\hline S5 & Uncharged & 1.42 & 0.15 & 64.5 \\
\hline S6 & $\begin{array}{c}\text { Deformed below yield } \\
\text { point+ 4 h pre-charged }\end{array}$ & 1.41 & 0.19 & 55.4 \\
\hline S7 & $\begin{array}{c}\text { Deformed beyond yield } \\
\text { point+ 4 h pre-charged }\end{array}$ & 1.40 & 0.15 & 51.7 \\
\hline
\end{tabular}

After the tensile tests, fracture surfaces of the failed samples were analysed ex-situ with an SEM LEO 1525 using an acceleration voltage of $20 \mathrm{kV}$.

\section{$\underline{\text { Results }}$}

\section{Effect of pre-charging time}


Fig. 4 shows the load-elongation curves of samples S1 to S4. The noise in the signal arises from interference between the RF power supply and the electronics of the tensile module, which could not be completely suppressed by shielding of the cables. At the beginning of the deformation experiment, the force value was not zero due to clamping and friction effects, which would also affect the apparent initial loading regime. Notably, for increasing deformations, the loading data converged for all samples and the maximum load value was approximately the same for all the tested samples, which is controlled by the failure of the uncharged thick side parts of the tensile sample (as shown in Fig. 1-c, only the centre-thinned area is charged). Importantly, all the charged specimens failed at lower elongations than the uncharged sample. Focusing only on the shaded areas, the elongation region from where cracks were initiated until final failure can be compared, i.e. the comparison of the crack propagation rather than initiation times. Comparing the shaded areas in the graph, it can be seen that the longer the charging time, the smaller the shaded area, i.e. the greater the decrease in the elongation of the samples.

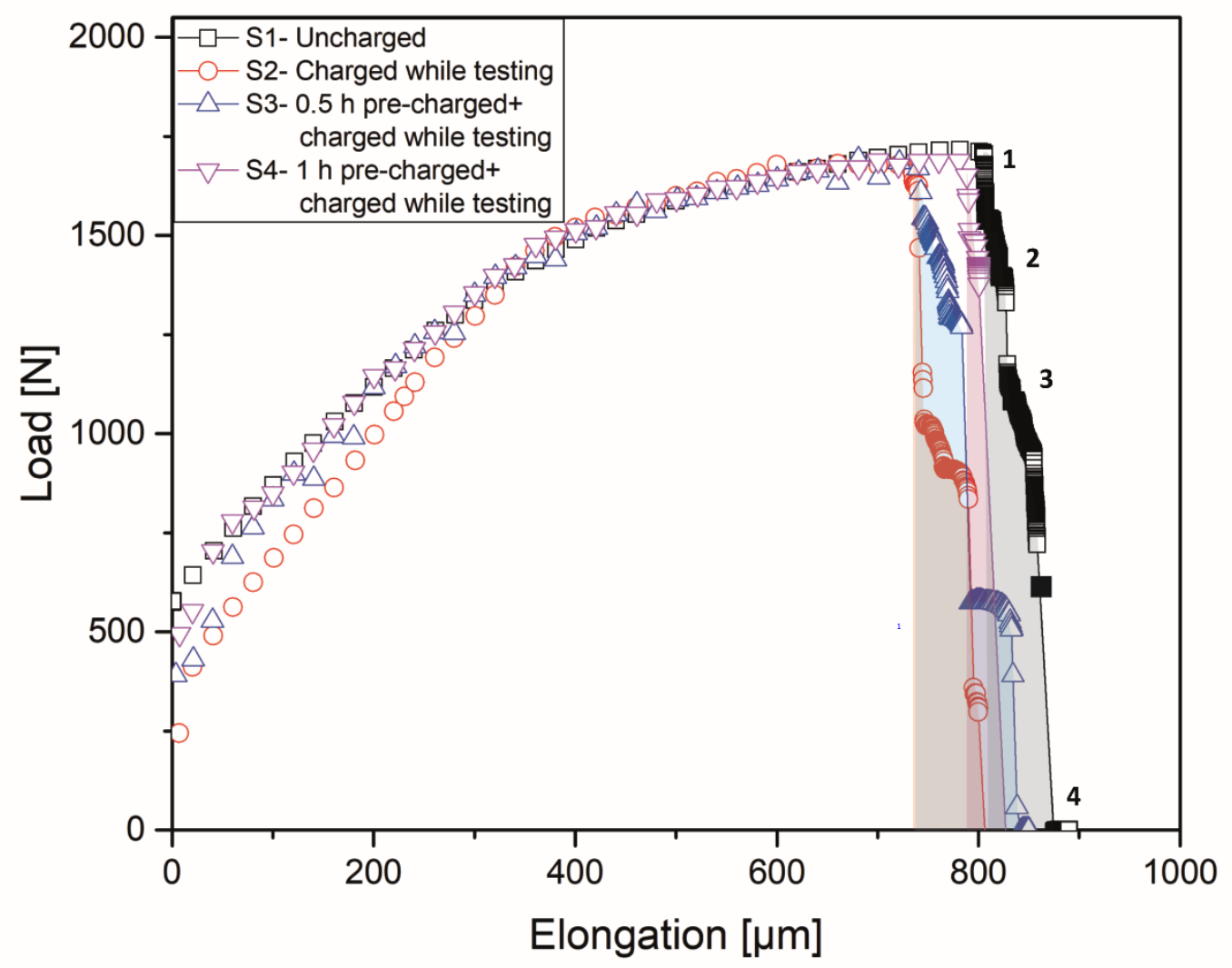

Fig. 4. Load-elongation curves of Alloy 718 S1, S2, S3 and S4 samples. Points 1 to 4 in the curve of the uncharged sample S1 correspond to the points where in-situ images were taken. Charged samples S2, S3 and S4 failed at lower elongation than uncharged S1 sample. The shaded areas show that with increasing charging time, the loss of elongation was higher

Fig. 5 shows the in-situ images of the centre of sample S1. The first decrease of the load corresponds to the appearance of a crack, while the last image relates to the final failure of the sample. 

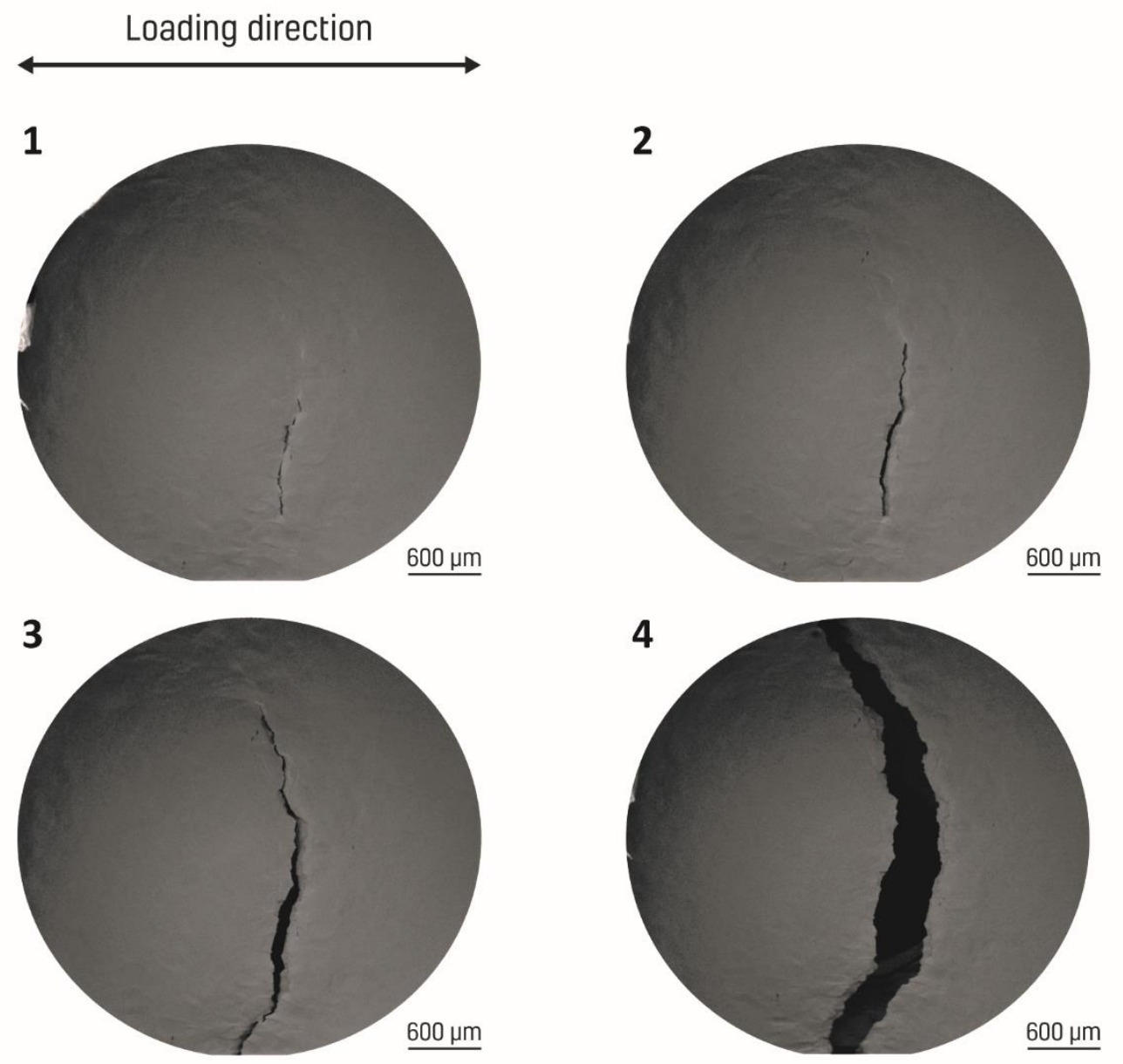

Fig. 5. In-situ images of Alloy 718 S1 (uncharged) sample. Points 1 to 4 correspond to the points marked in the load-elongation curve in Fig. 4, where the crack propagation stages can be correlated with the different load and elongation values

From the in-situ images, crack propagation can be readily monitored, and the linear intercept crack length was estimated for each sample at different loading steps, as shown in Fig. 6. All the charged samples failed before the uncharged one, but for comparison purposes, the crack initiation times were normalized to 0 s. Comparing the slope of the curves, which correspond to the crack propagation rate, S4 shows the fastest crack propagation rate. In S3, the crack propagation rate was lower than in the uncharged sample. Nevertheless, when the crack reached the uncharged parts of the sample, the propagation rate decreased. In the load-elongation curve in Fig. 4, it can be seen that there is at first a rather steep decrease in the load. Afterwards, there is a stage with more or less constant value, which corresponds to deformation of the uncharged parts of the sample, proving that there was an effect on the sample. Contrary to this, in the uncharged specimen, the crack propagation rate did not decrease when reaching the "thicker" parts of the sample. 


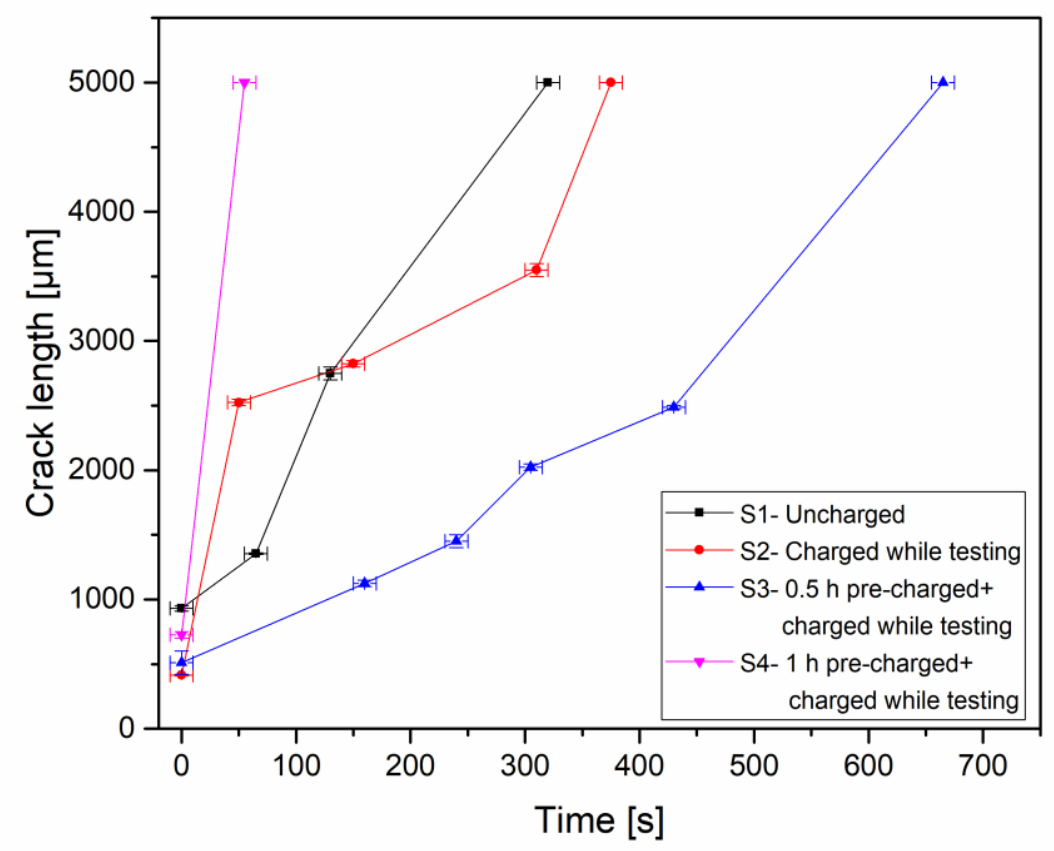

Fig. 6. Crack length over time for Alloy 718 S1, S2, S3 and S4 samples with crack initiation times normalized to 0 s. Considering that the slope of the curves represents the crack propagation rate, S4 shows the fastest rate

Fig. 7 shows the post-mortem fracture surfaces of the samples. Since these images were taken with a field emission SEM, the resolution is better than the in-situ images of Fig. 5, where a tungsten filament SEM was used. Sample S1 (Fig. 7-a) exhibits a typical ductile fracture surface with larger primary dimples and smaller secondary ones. Fig. 7-b shows the fracture surface of S2, with a completely different character than the uncharged one. This sample exhibits a brittle failure by decohesion along grain boundaries with rather smooth facets. Samples S3 and S4 have several different morphologies, as can be seen in Fig. 7-c and d. There are regions of microvoid coalescence, flat "featureless" regions and regions with striations, the last marked with dashed boxes in the figure. 

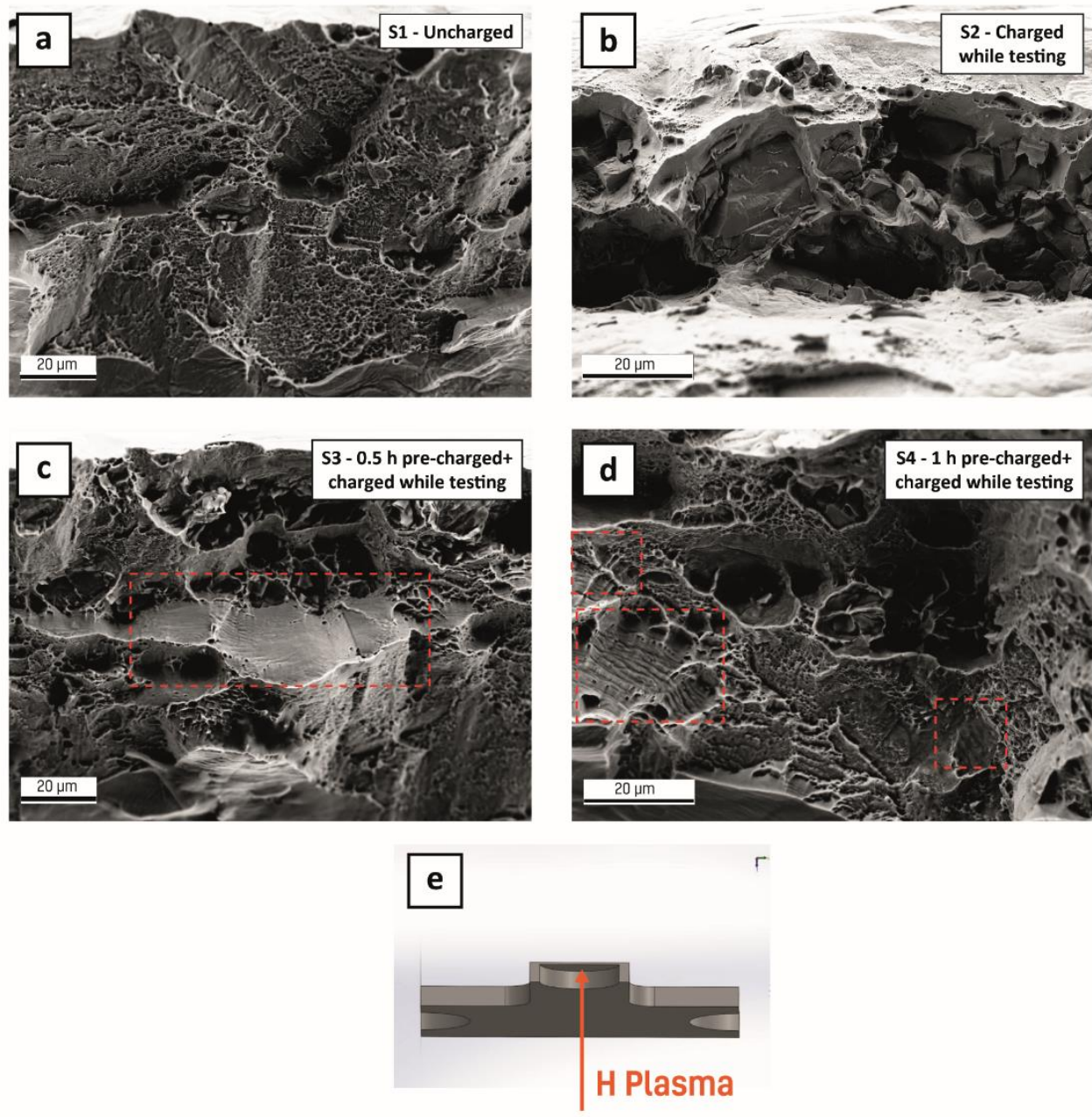

Fig. 7. Fracture surfaces of (a) S1, (b) S2, (c) S3 and (d) S4 Alloy 718 samples. (e) View of the cross section of the samples with the direction of plasma charging indicated. S1 (uncharged) sample shows a ductile failure while the charged samples show either intergranular or regions of "quasi-cleavage" (marked with dashed boxes) fracture behaviour

\section{Effect of pre-straining}

Fig. 8 shows the load-elongation curves of the second set of samples, where different amounts of prestrain were applied. Comparing the shaded areas of S5 and S6, it can be seen that, compared to the previous cases, the presence of $\mathrm{H}$ reduces the elongation until failure of the sample more significantly. From points 1 to 3 in S6, the crack propagates through the centre region of the sample, which is in contact with $\mathrm{H}$, as it can be seen in the in-situ images in Fig. 9. On the other hand, S7 shows a different character. As soon as a crack is initiated, point 5, the propagation was retarded, maintaining an almost constant value of load, until point 6 , followed by a decrease in the load to point 7 and another step of constant load before final failure. In this case, the shaded area of the deformed sample was larger than the one of the uncharged S5 sample, i.e. in S7 the crack propagation was retarded to a higher extent than samples S5 and S6. 


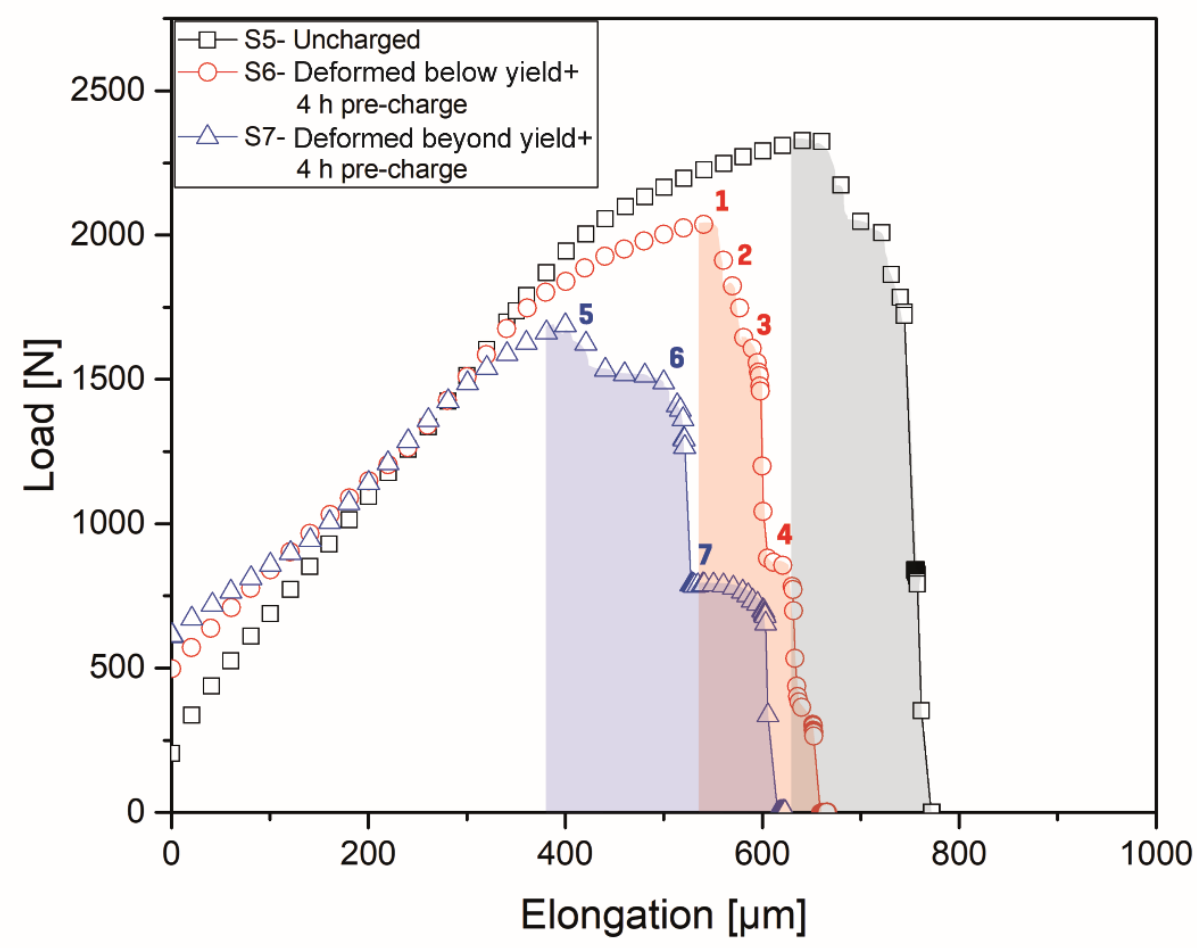

Fig. 8. Load-elongation curves of Alloy 718 S5, S6 and S7 samples depicting influence of pre-strain. Points 1 to 4 in the S6 curve correspond to the points where in-situ images were taken and 5 to 7 in the S7 curve show the regions where there are plateau regions of the force. The shaded areas show a reduction in elongation in the S6 charged and pre-strained below yield-sample compared to the uncharged sample but an increase in the S7 charged and pre-strained above yield-sample. 

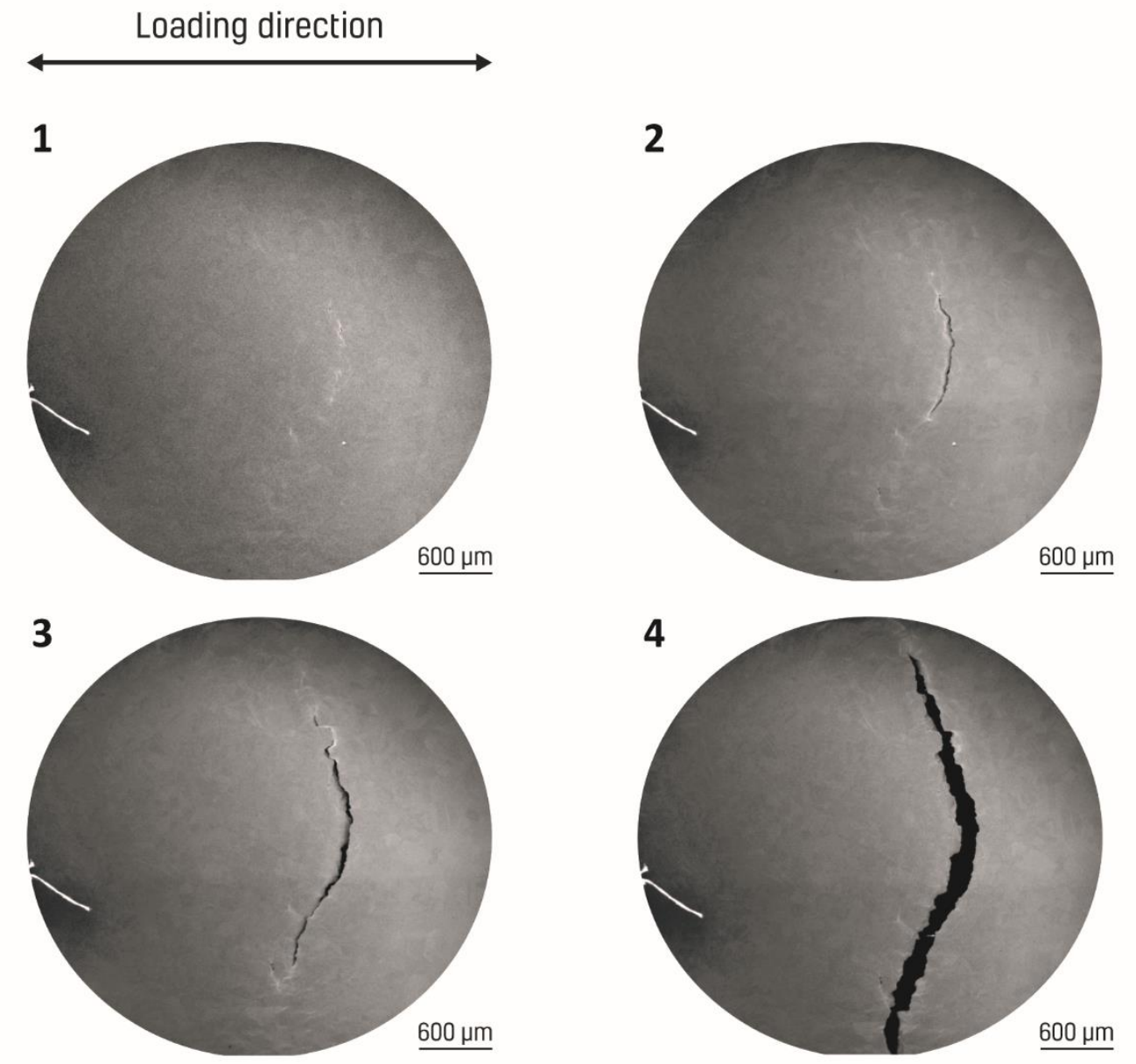

Fig. 9. In-situ images of Alloy 718 S6 (pre-strained before yield and 4 h pre-charged) sample. Points 1 to 4 correspond to the points marked in the load-elongation curve in Fig. 8. Crack initiation and propagation steps can be correlated with load and elongation values of the curve

As in the previous experiments, the crack length over time was calculated from the in-situ images, displayed in Fig. 10. The uncharged sample, S5, is the last one to fail. Comparing the time from which cracks are initiated until final failure, it can be seen that the crack propagation rate of S6 is higher than S5. However, S7 shows a slower propagation than the uncharged S5 sample (990 s of crack propagation compared with $570 \mathrm{~s}$ for S5). This is in agreement with the load-elongation curves in Fig. 8. 


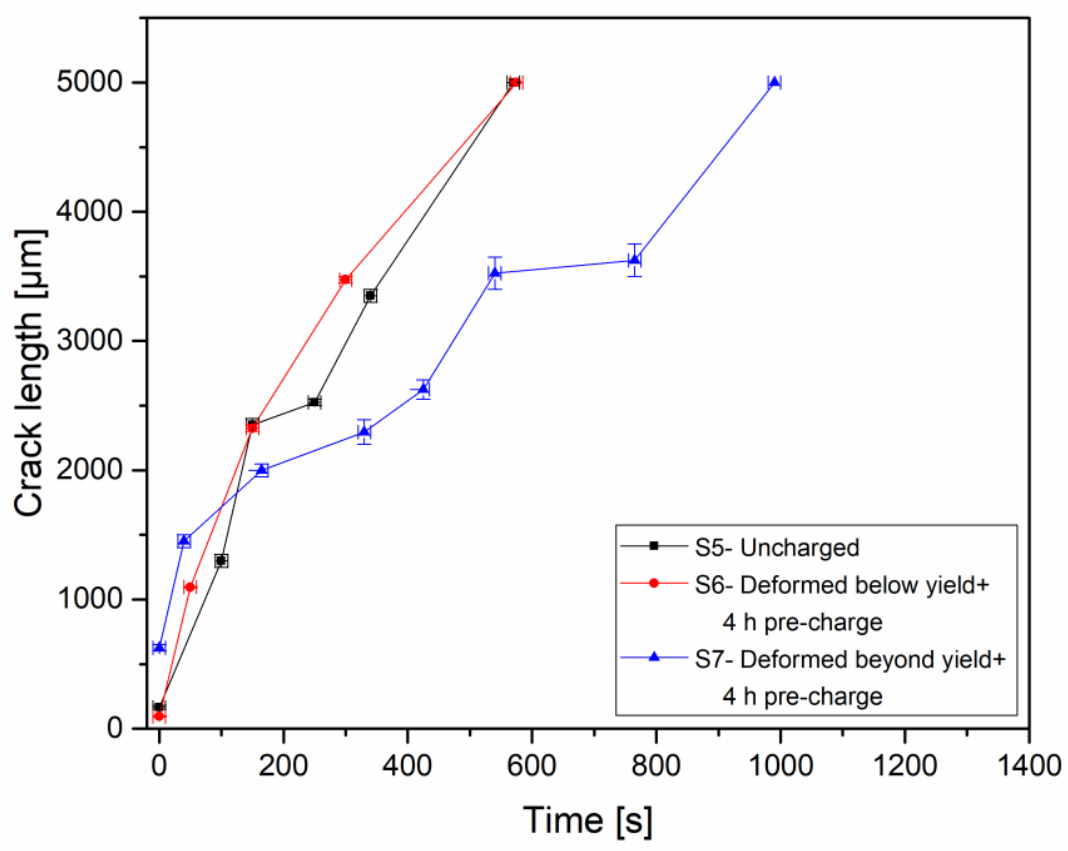

Fig. 10. Crack length over time for Alloy 718 S5, S6 and S7 samples with crack initiation normalized to $0 \mathrm{~s}$. The slope of the curves corresponds to the crack propagation rate. Samples S5 and S6 show a similar behaviour but the propagation rate in sample $S 7$ was retarded

Fig. 11 shows the fracture surfaces of the samples. The sample S5 without pre-strain, Fig. 11-a, exhibits a typical ductile failure where small dimples within large ones can be seen, similar to the uncharged sample of the previous set of samples. The inclusions present on the fracture surface, marked with arrows, are most likely formed during the production process of the alloy [46]. This was the only sample in which inclusions were seen. The fracture surface of sample S6 exhibits some similarities with S3 and S4. This specimen also shows dimples and regions with river markings indicated by dashed boxes. On the other hand, S7 presents to a large extent only dimples. 

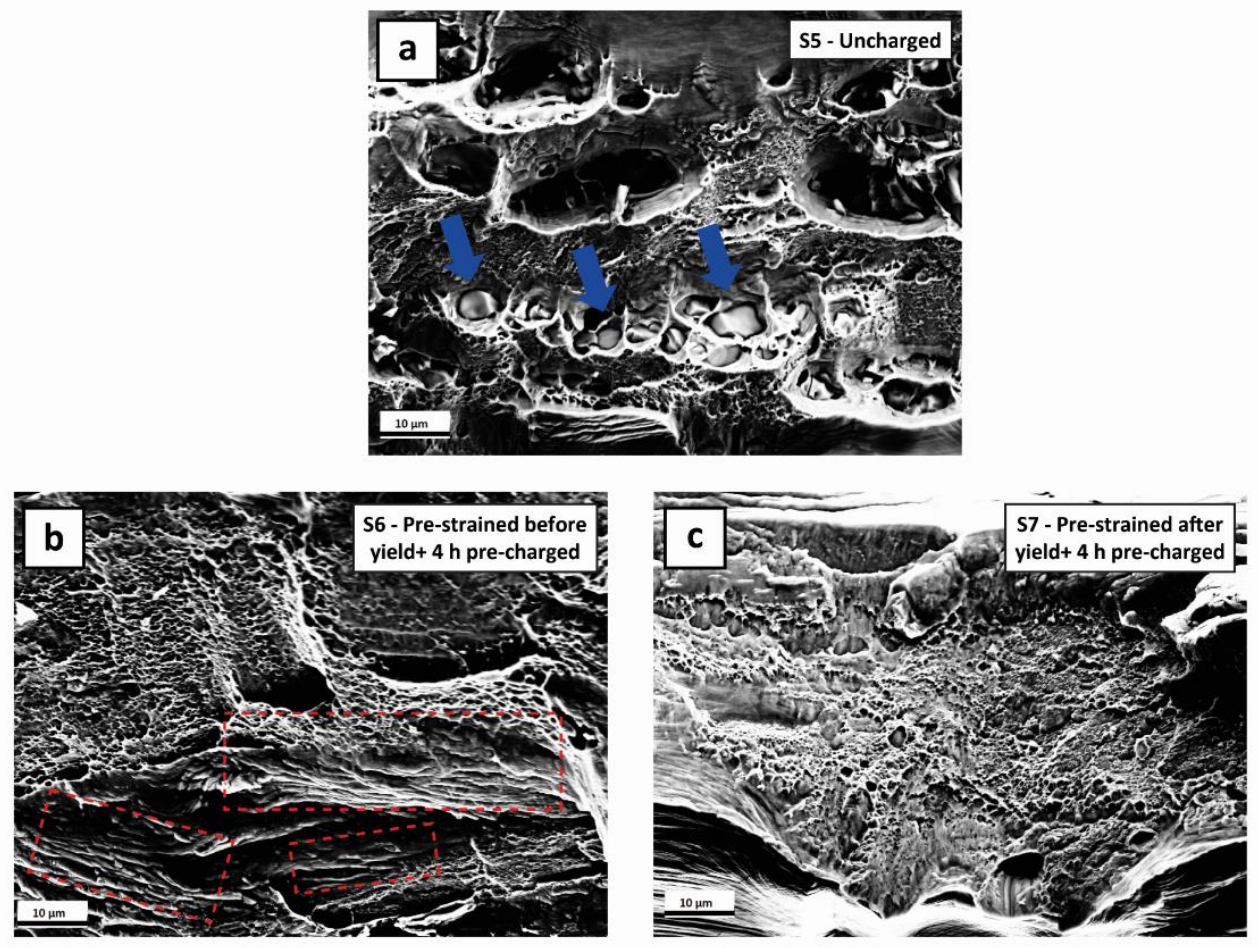

Fig. 11. Fracture surface of (a) S5, (b) S6 and (c) S7 Alloy 718 samples. The charging for all samples is from the bottom as shown in Fig. 7-d. Inclusions were present in S5 sample, marked with arrows in (a). S5 and S7 show a ductile fracture while "quasi-cleavage" regions can be seen in S6 sample, marked with dashed boxes in (b).

Moreover, optical micrographs of the top surface were taken after sample failure next to the fracture surface, as shown in Fig. 12. Mechanical twinning can be observed in the samples in the proximity to the fracture surface. 

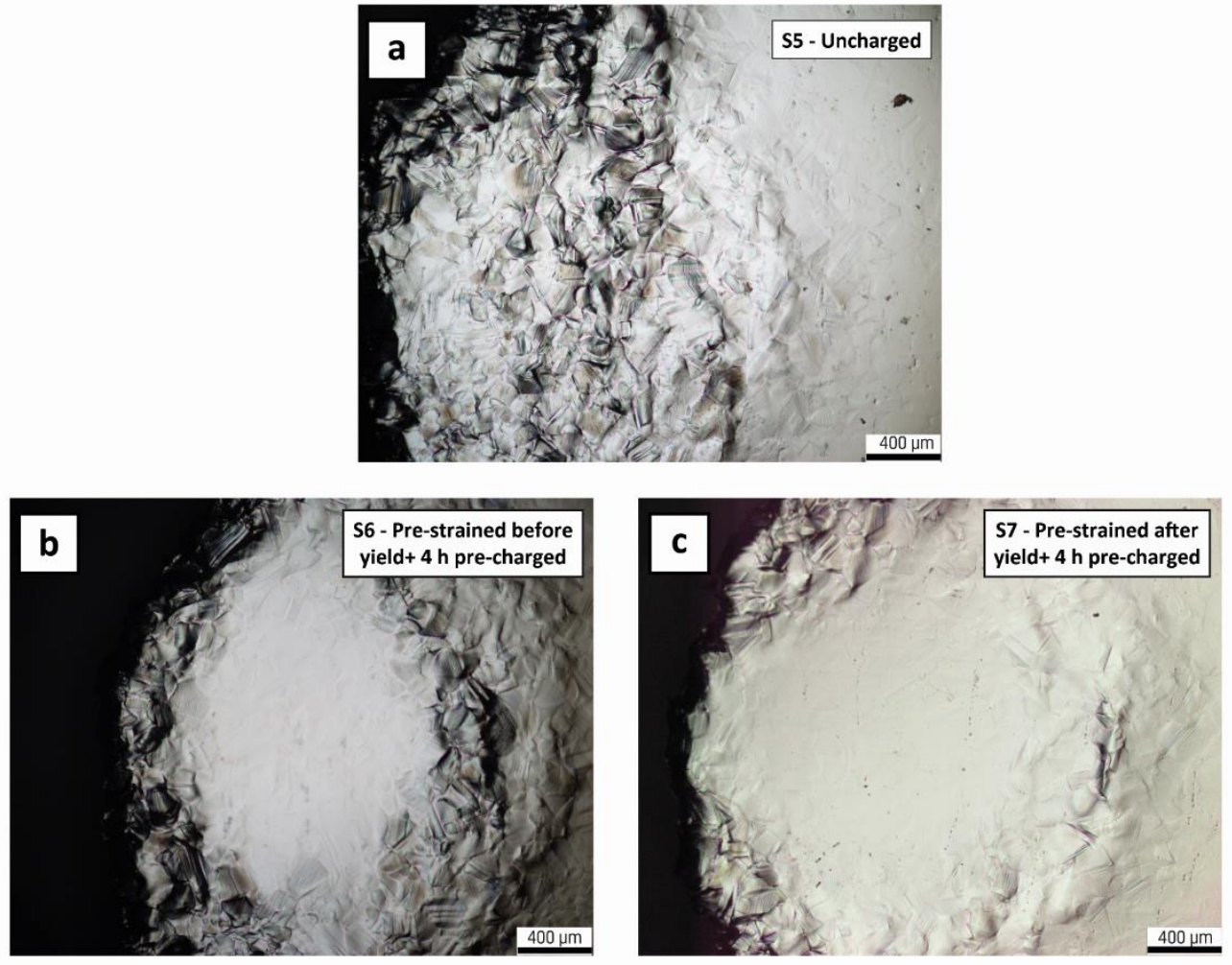

Fig. 12. Optical micrographs of (a) S5, (b) S6 and (c) S7 Alloy 718 samples showing deformation and mechanical twinning next to the fracture surface.

\section{$\underline{\text { Discussion }}$}

\section{Method}

The method developed allows direct charging of materials for the investigation of $\mathrm{H}$ effects for a wide range of sample sizes with the advantage of testing macroscopic samples. The simulation results in Fig. 2 confirmed that, although the geometry is not standardized, the stress distribution in the charged and thinned area is sufficiently homogenous, eliminating possible undesired stressed-driven $\mathrm{H}$ diffusion to regions with higher hydrostatic stresses in the sample.

An important advantage of this method is that samples can be continuously charged while testing, which is crucial for materials with high $\mathrm{H}$ diffusivity and simultaneously low $\mathrm{H}$ solubility, for example ferritic steels. Moreover, there is no risk of sample corrosion as can happen with electrochemical charging, with the possibility of sample failure. Furthermore, with cathodic charging there can be a pre-damage in the samples, which can alter the effect of H. For instance, it has been reported [47] that cathodic charging alone generated slip lines and surface and subsurface cracks. The pre-damage caused by the charging resulted finally in a reduction of yield strength and an increased embrittlement.

To the authors' knowledge, the presented method is the first one reported that combines in-situ charging and tensile testing inside an SEM, presenting no risk for the SEM even when the sample fractures. 


\section{Effect of pre-charging time}

In the load-elongation curves from Fig. 4, the elongation of S4 seems to be larger than S2 and S3. Nevertheless, if only the elongation is considered from the point where cracks are initiated (first drop in the load) until the final fracture of the sample, it can be seen that with increasing charging time the elongation was decreased. In the S4 sample, the load dropped abruptly from point 1 to point 2 (zero load), while in S2 and S3 samples failure was not so abrupt. This behaviour was also evidenced in the in-situ images and the crack propagation in Fig. 6. For S4 only two in-situ images of the crack were recorded, since the failure of the sample occurred immediately after crack initiation. Furthermore, as mentioned before, the crack propagation rate of S4 was the highest. In this context, sample S4 showed a greater susceptibility to $\mathrm{H}$ due to the higher amount of pre-charged $\mathrm{H}$. Contrary to this, although crack initiation of S2 and S3 was before S4, the propagation was slower, especially in the areas that were not in contact with the $\mathrm{H}$ source. A possible reason for this behaviour is that there is a gradient in $\mathrm{H}$ concentration, and since $\mathrm{H}$ diffusion in $\mathrm{Ni}$ is low $[48,49]$, there is not enough time for $\mathrm{H}$ to diffuse to the sides of the samples (which are not in direct contact with the plasma) so crack propagation is not accelerated in such areas, in contrast to the directly $\mathrm{H}$-charged regions.

In ductile crack growth, there is almost no emission of dislocation directly from crack tips due to strong bonding. Most of the egressing dislocations, around crack tips, produce crack blunting and plastic deformation rather than crack advance. The coalescence of large voids involves nucleation and growth of small voids, and large dimples with smaller dimples appear on fracture surfaces [50], as it can be seen in Figs. 7-a and 11-a in the uncharged specimens.

The morphologies of H-enhanced fractures can be unaffected or changed from ductile microvoid coalescence to quasi-cleavage, cleavage or intergranular failure. In sample S2, the fracture behaviour, Fig. 7-b, was clearly affected by $\mathrm{H}$ changing to a brittle intergranular failure dominated by grain boundary decohesion.

Regarding the flat "featureless" regions and the regions with striations of samples S3 and S4, they are referred in literature as "quasi-cleavage" [51] and occur when both transgranular cleavage and ductile failure operate together. Materials that fail with a quasi-cleavage mechanism usually show river markings, which are originated inside the grains and run approximately parallel to the crack propagation direction. These markings can be seen in Figs. 7-c, d and 11-b running parallel to the crack propagation direction, i.e. perpendicular to the loading direction.

Lynch explained the presence of dimples in the charged samples with his Adsorption Induced Dislocation Emission (AIDE) model [2]. It states that dislocation emission in the presence of $\mathrm{H}$ is different from crack growth in an inert environment. Dislocations are emitted from the crack tip on suitable inclined slip planes as a result of interatomic bonds weakening by $\mathrm{H}$. Consequently, a greater proportion of dislocation activity results in crack growth, the coalescence of cracks with voids occurs at lower strains (in accordance with the load-elongation curves in Fig. 4) and shallower dimples are produced on fracture surfaces.

Although the crack propagation rate is greater in S4, with the observation of fracture surfaces it seems that the S2 sample is more susceptible than S3 and S4. This behaviour can be explained considering the plasma conditions. Although all the samples were tested with the same bias voltage plasma, in the S2 sample the power supplied was $4 \mathrm{~W}$ compared to $7 \mathrm{~W}$ in the other two samples. This increase in power can increase the temperature 
of the sample, increasing the $\mathrm{H}$ diffusivity in the sample and thus decreasing the $\mathrm{H}$ concentration. Unfortunately, in the current realization it is not possible to measure (or actively control) the sample temperature during experiments, but this is planned to be implemented for future work.

\section{Effect of pre-straining}

According to the results presented, pre-straining the sample before yield (S6) shows similar $\mathrm{H}$ susceptibility as in the previous experiments. This specimen displayed similar effects as the charged samples in the previous set. The elongation was reduced and the crack propagation rate increased. Furthermore, the fracture surface exhibited a quasi-cleavage mode. Contrarily, it seems that pre-straining the sample to a post yield condition (S7) reduces the sensitivity for HE.

Ji. et al. [52] detected similar effect in $310 \mathrm{~S}$ stainless steel and they suggested that pre-strain hinders the formation of fresh mechanical twins and $\mathrm{H}$ delivery to twin boundaries, avoiding a high $\mathrm{H}$ concentration in twin boundaries. Since S7 exhibits lower susceptibility to detrimental $\mathrm{H}$ effects, it is possible that the $\mathrm{H}$ concentration was lowered at twin and grain boundaries. High-resolution SEM was used to compare the density of mechanical twins between the samples but no clear difference was observed. Another explanation for the behaviour of S7 could be that there is a strain hardening effect in the uncharged sides of the sample that lowers the crack propagation rate, giving rise to steps of constant load, as shown in Fig. 8.

\section{Conclusions and outlook}

A novel in-situ method for HE studies has been developed and successfully implemented. This methodology is based on in-situ continuously charging materials with H plasma inside an SEM and allows having high-resolution observation while deforming the material of interest. In addition, although $\mathrm{H}$ outgassing from the material cannot be avoided ( $\mathrm{H}$ arriving at the surface recombines and desorbs), there is a constant supply of $\mathrm{H}$, which leads to a dynamic equilibrium of the $\mathrm{H}$ concentration. It is worth mentioning that the standard tungsten filament SEM used for this work only provides limited resolution of in-situ images, which could be highly improved by transferring the setup to a new field emission gun SEM. Nevertheless, in the present proof-ofprinciple case, the observations were sufficient to monitor the sample deformation and crack propagation, and correlate them with the load-elongation curves.

With respect to the studied solution annealed Alloy 718 material, in all the charged samples, with the exception of S7 sample, the crack propagation rate was increased and the ductility decreased when $\mathrm{H}$ was present. Furthermore, with the in-situ images it was possible to detect that the crack propagation rates were decreased once the crack run into the regions that were not in contact with plasma, which were the last parts of the sample to fail.

Fracture surface observation of uncharged samples showed a typical ductile fracture with the presence of dimples. The charged samples, on the other hand, displayed either a brittle intergranular failure or a quasi-cleavage with river markings features. This difference could be attributed to a change in the sample temperature when applying more power to strike the plasma.

Future efforts will relate to modify the sample to introduce cracks in order to allow detailed crack microstructure interaction observations at higher magnifications, as well as detailed determination of the $\mathrm{H}$ concentration in the material. 


\section{Acknowledgments}

The authors gratefully acknowledge the financial support under the scope of the COMET program within the K2 Center "Integrated Computational Material, Process and Product Engineering (IC-MPPE)" (Project No 859480). This program is supported by the Austrian Federal Ministries for Transport, Innovation and Technology (BMVIT) and for Digital and Economic Affairs (BMDW), represented by the Austrian research funding association (FFG), and the federal states of Styria, Upper Austria and Tyrol.

\section{$\underline{\text { References }}$}

[1] Johnston B., Mayo M. C. Khare A. "Hydrogen: The energy source for the $21^{\text {st }}$ century". Technovation. 25(6): 569-585 (2005).

[2] Lynch S. P. "Hydrogen embrittlement phenomena and mechanisms". In: Vaja R.S., Shoji T. (Ed.) Stress Corrosion Cracking. Woodhead Publishing, Cambridge, pp 90-130 (2011).

[3] de Barbadillo J. J., Mannan S. K. “Alloy 718 for oilfield applications”. JOM. 64(2): 265-270 (2012).

[4] Johnson W. "On some remarkable changes produced in iron and steel by the action of hydrogen and acids". Nature 11: 393 (1875).

[5] Gerberich W. W., Oriani R., Lii M.-J., Chen T., Foecke T. "The necessity of both plasticity and brittleness in the fracture thresholds of iron”. Philos. Mag. A 63:1363 (1991).

[6] Lynch S. P. "Environmentally assisted cracking: Overview of evidence for an adsorption-induced localised slip process". Acta Metall. 36(10): 2639-2661 (1988).

[7] Birnbaum H. K., Sofronis P. "Hydrogen-enhanced localized plasticity- a mechanism for hydrogen-related fracture". Mater. Sci. Eng. A176: 191-202 (1994).

[8] Vehoff H., Neumann P. "Crack propagation and cleavage initiation in Fe-2.6\%-Si single crystals under controlled plastic crack tip opening rate in various gaseous environments". Acta Metall. 28(3): 265-272 (1980).

[9] Barnoush A., Vehoff H. "Hydrogen embrittlement of aluminum in aqueous environments examined by in situ electrochemical nanoindentation”. Scripta Mater. 58(9): 747-750 (2008).

[10] Barnoush A., Vehoff H. "Recent developments in the study of hydrogen embrittlement: Hydrogen effect on dislocation nucleation”. Acta Mater. 58(16): 5274-5285 (2010).

[11] Beachem C. D. "A new model for hydrogen-assisted cracking (Hydrogen "Embrittlement")". Metall. Mater. Trans. B. 3(2): 441-455 (1972).

[12] Oriani O. A., Josephic P. H. "Equilibrium aspects of hydrogen-induced cracking in steels". Acta Metall. 22(9): 1065-1074 (1974).

[13] Tabata T., Birnbaum H. K. "Direct observations of the effect of hydrogen on the behaviour of dislocations in iron". Scripta Metall. 17: 947- 950 (1983).

[14] Robertston I. M., Birnbaum H. K. "An HVEM study of hydrogen effects on the deformation and fracture of nickel”. Acta Metall. 34: 353- 366 (1986).

[15] Matsui M., Kimura H. "The effect of hydrogen on the mechanical properties of high purity iron". Mater. Sci. Eng. 40: 207-216 (1979).

[16] Nagumo M., Nakamura M., Takai K. "Hydrogen thermal desorption relevant to delayed-fracture susceptibility of high-strength steels". Metall. Mater. Trans. A. 32A: 339-347 (2001).

[17] Lynch S. P. “Mechanisms of hydrogen-assisted cracking”. Met. Forum. 2: 189-200 (1979). 
[18] Nagumo M., Yagi T., Saitoh H. "Deformation-induced defects controlling fracture toughness of steel revealed by tritium desorption behaviours". Acta Mater. 48: 943-951 (2000).

[19] He S., Ecker W., Pippan R., Razumovskiy V. I. "Hydrogen-enhanced decohesion mechanism of the special

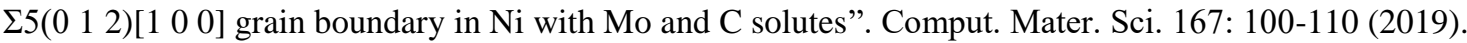

[20] Lynch S. P. "Metallographic contributions to understanding mechanisms of environmentally assisted cracking”. Metallography. 23: 141-171 (1989).

[21] Lynch S. P. "Comments on "A unified model of environmental assisted cracking”. Scripta Mater. 61: 331334 (2009).

[22] Birnbaum H. K., Robertson I. M., Sofronis P. "Hydrogen effects on plasticity”. In: Kubin L., Hirth K. P. (Eds.) Disocations in Solids. Elsevier, Amsterdam, pp. 249-293 (2009).

[23] Birnbaum H. K. "Mechanisms of hydrogen related fracture of metals". In: Moody N. R., Thompson A. W. (Eds.) Hydrogen effects on material behaviour: The Minerals, Metals and Materials Society. pp. 639-658 (1990).

[24] Birnbaum H. K., Robertston I. M., Sofronis P., Teter D. In: Magnin T. (Ed.) Corr.-def. interact. Trans Tech, Great Britain, pp 172-195 (1997).

[25] Bhadeshia H. K. "Prevention of hydrogen embrittlement in steels". ISIJ Int. 56: 24-36 (2016).

[26] Robertson I. M., Sofronis P., Nagao A., Martin M. L., Wang S., Gross D. W. "Hydrogen embrittlement understood". Metall. Mater. Trans. B. 46: 1085-1103 (2015).

[27] Barnoush A., Vehoff H. "In situ electrochemical nanoindentation: a technique for local examination of hydrogen embrittlement”. Corr. Sci. 50: 259-267 (2008).

[28] Pippan R., Wurster S., Kiener D. "Fracture mechanics of micro samples: Fundamental considerations". Materials and Design. 159: 252-267 (2018).

[29] Conrads H., Schmidt M. "Plasma generation and plasma sources". Plasma Sources Sci. Technol. 9: 441-454 (2000).

[30] Wan D., Deng Y., Barnoush A. "Hydrogen embrittlement effect observed by in-situ hydrogen plasma charging on a ferritic alloy". Scripta Mater. 151: 24-27 (2018).

[31] Wan D., Deng Y., Hammer Meling J. I., Alvaro A., Barnoush A. "Hydrogen-enhanced fatigue crack growth in a single-edge notched tensile specimen under in-situ hydrogen charging inside an environmental scanning electron microscope". Acta Mater. 170: 87-99 (2019).

[32] Vaghela N. "RF (13.56 MHz) Impedance Matching”. Huettinger Electronic Inc. http://www.if.ufrgs.br/ ckrug/pvd/rf-1.pdf. Accessed 3 September 2019.

[33] Abaqus Unified FEA-SIMULIATM by Dessault Systèmes®, (n.d.). https://www.3ds.com/productsservices/simulia/products/abaqus/ (accessed December 5, 2019)

[34] Stroth U. Plasmaphysik-Phänomene, Grundlagen und Anwendung. Springer Spektrum, Garching, Germany (2011).

[35] Magnus F., Gudmundsson J. T. "Digital smoothing of the Langmuir probe I-V characteristic". Rev. Sci. Instrum. 79, 073503 (2008).

[36] Chen F. F. "Lecture notes on Langmuir Probe Diagnostics". In Mini-Course on Plasma Diagnostics, IEEEICOPS meeting, Jeju, Korea (2003).

[37] Liu L., Zhai C., Lu C., Ding W., Hirose A., Kobayashi K. F. "Study of the effect of $\delta$ phase on hydrogen embrittlement of Inconel 718 by notch tensile tests”. Corr. Science. 47: 355-367 (2005).

[38] Tarzimoghadam Z., Ponge D., Klöwer J., Raabe D. "Hydrogen-assisted failure in Ni-based superalloy 718 studied under in situ hydrogen charging: The role of localized deformation in crack propagation". Acta Mater. 128: 365-374 (2017). 
[39] Zhang Z., Obasi G., Morana R., Preuss M. "Hydrogen assisted crack initiation and propagation in a nickelbased superalloy”. Acta Mater. 113: 272-283 (2016).

[40] Zhang Z., Obasi G., Morana R., Preuss M. "In-situ observation of hydrogen induced crack initiation in a nickel-based superalloy”. Scripta Mat. 140: 40-44 (2017).

[41] Drexler A., Oberwinkler B., Primig S., Turk C., Povoden- Karadeniz E., Heinemann A., Ecker W., Stockinger M. "Experimental and nummerical investigations of the $\gamma$ " and $\gamma$ ' precipitation kinetics in Alloy 718”. Mater. Sci. Eng. A. 723: 314-323 (2018).

[42] Drexler A., Fischersworring-Bunk A., Oberwinler B., Ecker W., Gänser H.-P. “A microstructural based creep model applied to alloy 718”. Int. J. Plast. 105: 62-73 (2018).

[43] Jebaraj J. J. M., Morrison D. J., Suni I. I. "Hydrogen diffusion coefficient through Inconel 718 in different metallurgical conditions". Corr. Sci. 80: 517-522 (2014).

[44] Mutzke, A., Schneider, R., Eckstein, W., Dohmen, R.; Schmid, K., von Toussaint, U., Badelow, G. (2019) "SDTrimSP Version 6.00” (IPP 2019-2). Garching: Max-Planck-Institut für Plasmaphysik.

[45] Tanabe T., Furuyama Y., Imoto S. "Hydrogen ion permeation through metals". J. Nulc. Mater. 145-147: 305308 (1987).

[46] Mitchell A. “Superalloys 718, 625 and various derivatives”. In: Loria E. A. (Ed.) The Minerals, Metals \& Materials Society. pp 15-27 (1991).

[47] Lu X., Wang D., Wan D., Zhang Z. B., Kheradmand N., Barnoush A. "Effect of electrochemical charging on the hydrogen embrittlement susceptibility of alloy 718”. Acta Mater. 179: 32-48 (2019).

[48] Birnbaum H. K., Wert C. A. "Diffusion of hydrogen in metals”. Ber. Bunsen-Ges. 72(8): 806-816 (1972).

[49] Drexler A., Depover T., Verbeken K., Ecker W. "Model-based interpretation of thermal desorption spectra of Fe-C-Ti alloys". J. Alloys Compd. 789: 647-657 (2019).

[50] Lynch S. "Mechanistic and fractographic aspects of stress corrosion cracking”. Corros. Rev. 30: 105-123 (2012).

[51] Martin M. L., Fenske J. A., Liu G. S., Sofronis P., Robertson I. M. "On the formation and nature of quasicleavage fracture surfaces in hydrogen embrittled steels". Acta Mater. 59(4): 1601-1606 (2011).

[52] Ji H., Park I-J., Lee S.-M., Lee Y.-K. "The effect of pre-strain on hydrogen embrittlement in $310 \mathrm{~S}$ stainless steel”. J. Alloys Compds. 598: 205-212 (2015). 